\title{
A robótica educacional como ferramenta multidisciplinar: um estudo de caso para a formação e inclusão de pessoas com deficiência
}

\author{
Lidia Lopes* \\ Larissa Medeiros Marinho dos Santos** \\ Luis Fernando Freire de Souza*** \\ Marcio Falcão Santos Barroso ${ }^{* * * *}$ \\ Cleuzilaine Vieira da Silva**** \\ Bruna Reis Serpa****** \\ Eduardo Bento Pereira******
}

\section{Resumo}

Este trabalho apresenta os resultados do projeto de extensão com interface a pesquisa "A Robótica e a Inclusão Social: Tecnologia e Acessibilidade Aplicadas ao Ensino", no qual os objetivos primordiais foram de estabelecer uma dinâmica de interação com a comunidade externa da UFSJ oferecendo aulas de introdução de robótica para alunos do ensino fundamental e médio de escolas públicas de São João del-Rei com baixo desempenho no ENEM. Incluindo também, nesse trabalho, alunos com deficiência dessas instituiçóes regulares de ensino. No total, participaram do trabalho oito escolas. Dentre os alunos, quatro surdos, um esquizofrênico, um com síndrome de Asperger e um com déficit de inteligência. A hipótese colocada em cheque nesse trabalho é se em um grupo heterogêneo irão se sobressair as qualidades individuais de cada elemento, para o bem do grupo, em detrimento de seus limitantes físicos e/ou cognitivos. Foram desenvolvidas atividades com o intuito de proporcionar maior interação e trabalho em equipe entre os alunos durante as aulas. Ao final desse trabalho, foi proposta a avaliação do projeto, sendo essa baseada nas discussóes referentes às observaçôes realizadas pelos instrutores do curso de robótica (graduandos em Engenharia Elétrica), alunos de Psicologia que acompanharam as aulas e professores orientadores do projeto. Com relação à hipótese que foi colocada a princípio no projeto, após a análise sistemática das discussões e questionários pelos estudantes e professores da Engenharia Elétrica e Psicologia, concluiu-se que o trabalho em equipe dos alunos superou suas limitações físicas e cognitivas.

Palavras-chave: Educação especial; Robótica; Inclusão.

\footnotetext{
* Mestranda em Psicologia pela Universidade Federal de São João Del-Rei, São João del-Rei, Minas Gerais, Brasil.

** Professora doutora da Universidade Federal de São João Del-Rei, São João del-Rei, Minas Gerais, Brasil.

*** Graduando em Engenharia Elétrica pela Universidade Federal de São João Del-Rei, São João del-Rei, Minas Gerais, Brasil.

**** Professor doutor da Universidade Federal de São João Del-Rei, São Joẫo del-Rei, Minas Gerais, Brasil.

***** Mestranda em Processos Socioeducativos e Práticas Escolares pela Universidade Federal de São João Del -Rei, São João del-Rei, Minas Gerais, Brasil.

****** Graduanda em Psicologia pela Universidade Federal de São João Del-Rei, São João del-Rei, Minas Gerais, Brasil.

******* Professor doutor assistente da Universidade Federal de São Joâo Del-Rei, São João del-Rei, Minas Gerais, Brasil.
} 


\section{The educational robotics as multi-disciplinary tool: a case study for formation and inclusion of persons with disabilities}

\section{Abstract}

This paper presents the results of the extension project with interface the research "Robotics and Social Inclusion: Technology and Accessibility Applied to Teaching", in which the primary objective was to establish a dynamic of interaction with the external community of UFSJ offering introduction to robotics classes to elementary and high school students of public schools in São João del Rei that achieved a low result on ENEM. This work also includes students with disabilities from these regular educational institutions. In total, eight schools participated in this project, and among the students there were four deaf, one schizophrenic, one with a sprinkle syndrome and one with intelligence deficit. The hypothesis put in check in this project was whether in heterogeneous group individual qualities of each element would stand out, for the good of the group, in detriment of their physical or cognitive limiting. Activities were developed to reach this purpose with the aim to offer more interaction and group work among students during the classes. In the end it was proposed the evaluation of the project based on discussions concerning the observations made by the robotic course instructors (Electric Engineering Students), Psychology students that accompanied the classes and professors who guided the project. Thus, in relation to the hypothesis that was primary in the project, after the systematic analysis of discussions and questionnaires by the Electrical Engineering and Psychology students and professors, it was concluded that the students' team work overcame their physical and cognitive limitations.

Keywords: Special education; Robotics; Inclusion.

\section{Introdução}

"Novas realidades e novos paradigmas emergem na sociedade humana, nos dias de hoje. Uma sociedade mais permeável à diversidade questiona seus mecanismos de segregaçáo e vislumbra novos caminhos de inclusão social da pessoa com deficiência" (GALVÂO FILHO e DAMASCENO, 2008). Estes argumentos ganham repercussão e proporcionam novas pesquisas e discussóes na área, possibilitando difusão e permeabilidade para a formulação de novas concepções (GALVÃO FILHO e DAMASCENO, 2008).

As diferenças experimentadas por indivíduos com necessidades educacionais especiais podem, com o que temos até o momento, tornar-se uma barreira ao aprendizado dessas crianças. Desenvolver projetos com o intuito de disponibilizar recursos de robótica, acessibilidade e tecnologias assistivas pode ser uma forma efetiva para proporcionar a diminuição das barreiras enfrentadas pela deficiência, proporcionando, dessa forma à inserção desses indivíduos em locais propícios a aprendizagem e desenvolvimento cultural (GALVÃO FILHO e DAMASCENO, 2008). 
A introdução de atividades relacionadas à robótica nas escolas pode contribuir para despertar o interesse de estudantes do ensino fundamental, médio e com necessidades educacionais especiais para as tecnologias atuais. Também pode contribuir de maneira relevante para as diversas atividades que podem ser desenvolvidas de forma multidisciplinar, ou seja, com o envolvimento de várias disciplinas, proporcionando a interação entre os alunos e difundindo o conhecimento. A busca pela solução de um novo problema proporciona aos alunos a construção de um ambiente de pesquisa, no qual permite instigar o estudante a pensar, interagir e questionar os colegas de sala de aula, além de consultar especialistas das diversas áreas dentro e fora do ambiente escolar. A robótica educacional, por apresentar conteúdos multidisciplinares, possibilita aos envolvidos o estudo do método científico vivenciado na prática de forma lúdica e atraente na montagem e programação dos robôs para várias situaçóes e desafios (PIO et al, 2006).

Tendo em vista todos esses aspectos, este trabalho apresenta os resultados de um projeto de extensão com interface em pesquisa, nomeado "A Robótica e a Inclusão Social: Tecnologia e Acessibilidade Aplicadas ao Ensino", sendo este desenvolvido por integrantes do Grupo de Controle e Modelagem (GCOM) em parceria com o Núcleo de Pesquisa em Acessibilidade, Diversidade e Trabalho (NACE) da Universidade Federal de São João del-Rei (UFSJ). Tem como base teórica o modelo da teoria Bioecológica do desenvolvimento, de Urie Bronfenbrenner (1979, 1996, 2011). Neste projeto, objetivou-se primordialmente estabelecer uma dinâmica de interaçấo com a comunidade externa da UFSJ no que diz respeito à introduçấo da robótica no ensino fundamental e médio de escolas públicas com baixo desempenho no Exame Nacional do Ensino Médio (ENEM), incluindo, também, estudantes com deficiência dessas mesmas instituiçóes. Finalmente, a proposta foi identificar se em um grupo heterogêneo sobressairia as qualidades individuais de cada elemento, para o bem do grupo, em detrimento de seus limitantes físicos e/ou cognitivos.

\section{Referencial teórico}

Robótica educacional ou robótica pedagógica são termos que caracterizam formas de ensino utilizando "materiais de sucata ou kits de montagem compostos por peças diversas, motores e sensores controláveis por computador e softwares que permitam programar o funcionamento dos modelos montados". Essa forma de ensino propốe a construção e controle de robôs que funcionam de forma programada pelo aluno para a realizaçáo dos desafios propostos (MENEZES e SANTOS, 2002).

Pesquisas envolvendo a robótica educacional já foram feitas por esse grupo (SOUZA, 2012; REIS, 2011, 2012 e 2015), mas o diferencial do projeto aqui citado é a participação de crianças com deficiência. Existem, no Brasil, vários pesquisadores que trabalham com robótica educacional. Um grupo de pesquisadores do Rio Grande do Norte, por exemplo, tem várias publicaçôes que relatam o uso da robótica para ensino. Há teses de doutoramento (SILVA, 2009), com a proposta do desenvolvimento de um software, o RoboEduc, criado especialmente para que os participantes controlassem e programassem os protótipos nas oficinas oferecidas pelos pesquisadores. Dissertaçôes de Mestrado (SILVA, 2010), com o tema da possibilidade de inser- 
ção sócio-digital. E artigos publicados pelos mesmos pesquisadores, relatando experiências com o ensino da robótica (SILVA, 2008; ZILLI, 2004; AZEVEDO, 1999).

Pesquisadores de Santa Catarina (SANTOS, POZZEBON e FRIGO, 2013; ZILLI, 2004), Bahia (AMORIN, 2013), Rio Grande do Sul (RODRIGUES, 2009) e também da USP (STEFFEN, 2002) trabalham com a robótica educacional. O primeiro citado relata uma experiência do uso da robótica na educação especial na disciplina de matemática para crianças do ensino especial e do ensino regular, entre seis a oito anos, sendo este o único artigo encontrado que relaciona robótica a educação especial.

Foram encontrados artigos sobre robótica educacional baseados em conceitos como o de "Inteligências múltiplas", "Ensino por competências", "Construtivismo" e "Construcionismo" de Howard Gardner, Philippe Perrenoud, Jean Piaget, Seymour Papert, respectivamente (STEFFEN, 2002), e pesquisas baseadas em Vygotsky, utilizando os conceitos de Zona de Desenvolvimento Proximal (ZILLI, 2004; SILVA, 2008). Neste trabalho, foi proposto como referencial a teoria Bioecológica do desenvolvimento, de Urie Bronfenbrenner (BRONFENBRENNER, 1979, 1996, 2011), que é derivada, segundo o autor, das suas experiências com Kurt Lewin e da fórmula clássica que indica que comportamento é uma função conjunta da pessoa e do ambiente $[\mathrm{C}=\mathrm{f}(\mathrm{P}, \mathrm{M})]$. O modelo proposto por Bronfenbrenner defende que o desenvolvimento constitui uma interação recíproca entre a pessoa e seu contexto através do tempo. A proposta é que para a compreensão do desenvolvimento da pessoa sejam estudados quatro núcleos que ele considera serem inter-relacionados: o Processo, a Pessoa, o Contexto e o Tempo (PPTC), em uma perspectiva não reducionista. Dentre o que ele chama de contextos: micro, meso, exo e macrossistemas. Microssistema é o ambiente onde a pessoa desenvolve suas interaçóes mais próximas e o macrossistema se refere ao contexto mais amplo no tempo e espaço em que a pessoa se insere: valores, crenças, culturas. No projeto de robótica, pode-se avaliar interferências tanto no que se refere ao microssistema das crianças, pois as aulas de robótica eram um espaço onde elas desenvolviam determinados papéis em uma relaçáo face a face com colegas e professores, quanto em relação ao macrossistema, pois as aulas de robótica incluindo pessoas com deficiência mudaram a ideia impregnada na cultura da sociedade moderna de que pessoas com deficiência são incapazes de exercerem as mesmas atividades das pessoas não deficientes. Processo é definido como relação entre o ambiente e as características da pessoa em desenvolvimento. Além de também utilizar como base a teoria de Vygotsky (REGO, 2002, p. 58), que ressalta que "o desenvolvimento está intimamente relacionado ao contexto sociocultural em que a pessoa se insere e se processa de forma dinâmica (e dialética) através de rupturas e desequilíbrios provocadores de contínuas reorganizaçóes por parte do indivíduo" sendo de fundamental importância o papel da interação social como mediadora na construção da subjetividade, dos parâmetros históricos e culturais, tornando essa interação e o uso da robótica motivadores no processo de ensino-aprendizagem.

A motivação do aluno é uma variável relevante do processo ensino/aprendizagem, na medida em que o rendimento escolar não pode ser explicado unicamente por 
conceitos como inteligência, contexto familiar e condição socioeconômica. Por esse motivo, os autores sublinham que, através da motivaçấo, consegue-se que o aluno encontre razóes para aprender, para melhorar e para descobrir e rentabilizar competências. Assim, a motivação é primordial no desempenho acadêmico dos estudantes e na apropriação total às solicitações do ambiente escolar (LOURENÇO e PAIVA, 2010). Consideramos o uso da robótica como forma de inclusão na educação, um fator motivador para os participantes, tanto para os com deficiência como para os sem deficiência, além de ser um instrumento para facilitar a relação entre eles, incentivando o trabalho em equipe e outros processos que serão citados no decorrer deste artigo.

\section{Metodologia}

Neste projeto, foram propostos cursos de robótica educacional, sendo esses divididos por ciclos ou módulos que vão do básico ao avançado. Cada ciclo pode ser cursado no período de dois, quatro ou seis meses. A definiçáo desses períodos foi baseada na experiência obtida em projetos de extensáo anteriores, desenvolvidos na UFSJ. A metodologia para implementação desse projeto consistiu, de forma resumida, em três etapas: seleção do público alvo, curso de robótica educacional e avaliação do projeto. É importante ressaltar que a seleção dos bolsistas e voluntários para o desenvolvimento do projeto, tal como a sua preparaçáo para as aulas de robótica, precedeu tais etapas. As aulas foram filmadas e gravadas para possível análise posterior.

\section{Seleção do público alvo}

Os cursos foram direcionados a estudantes de escolas públicas com prioridade para aquelas com resultados desfavoráveis no ENEM e sediadas em São João del-Rei - MG. Assim, este projeto teve como participantes crianças e adolescentes do ensino fundamental, médio, incluindo estudantes com deficiência, com faixa etária entre dez e vinte anos. Os estudantes de dez a quatorze anos foram classificados nas turmas de nível 1 e de quinze a vinte anos nas turmas de nível 2. Foram convidadas a participarem desse trabalho sete escolas da cidade de São João del-Rei, mas uma delas não se interessou. De cada escola foram selecionados pelos diretores e professores da própria instituição oito alunos com variados graus de desempenho escolar. No total, ao início desse projeto, participaram sessenta e quatro crianças e adolescentes, sendo quatro surdos, um esquizofrênico, um com síndrome de Asperger e um com déficit de aprendizagem.

\section{Curso de robótica educacional}

O curso de robótica educacional foi ministrado por um instrutor e auxiliado por quatro monitores dos cursos de engenharia, além do acompanhamento de um interprete de LIBRAS (Língua Brasileira de Sinais) para os estudantes surdos e um graduando em psicologia para acompanhamento das aulas. As aulas foram realizadas no LEROE (Laboratório de Ensino de Robótica Educacional) da UFSJ, que dispóe de arenas de treinamento, computadores, bancadas, datashow e kits didáticos de robótica. $\mathrm{O}$ curso foi elaborado tendo um total de vinte aulas, tendo duração de duas horas por aula, realizadas duas vezes por semana, durante um período de três 
meses. As aulas foram oferecidas no contra turno das aulas regulares. Visando maior interação e trabalho em equipe, os participantes foram divididos em até dezesseis participantes por turma, subdivididos em grupos de quatro. As aulas aconteceram conforme descrito na tabela abaixo:

\begin{tabular}{|c|c|c|c|}
\hline Aulas & Temas & Atividades desenvolvidas & Materiais utilizados \\
\hline $\begin{array}{l}\text { Aula 1: } \\
\text { Montando } \\
\text { estruturas }\end{array}$ & $\begin{array}{l}\text { Montagem } \\
\text { mecânica }\end{array}$ & $\begin{array}{l}\text { Construção de um protótipo } \\
\text { no formato de um veículo } \\
\text { montado com o kit didático } \\
\text { da Modelix }{ }^{\otimes} \text { acionado por um } \\
\text { motor de corrente contínua. }\end{array}$ & Kit didático da Modelix ${ }^{\oplus}$ \\
\hline $\begin{array}{c}\text { Aula 2: } \\
\text { Eletrizando }\end{array}$ & Eletrônica & $\begin{array}{l}\text { Montagens de circuitos em } \\
\text { série e paralelo para acender } \\
\text { e observar a variaçáo da } \\
\text { iluminação de um ou mais } \\
\text { LEDs (Light emitter diode } \\
\text { - Diodo Emissor de Luz) } \\
\text { combinados. }\end{array}$ & $\begin{array}{l}\text { Protoboards, baterias, } \\
\text { LEDs, botoeiras, } \\
\text { resistores e fios para } \\
\text { conexão. }\end{array}$ \\
\hline $\begin{array}{l}\text { Aula 3: } \\
\text { Pensando } \\
\text { pelo robô }\end{array}$ & Programação & $\begin{array}{l}\text { Introdução à lógica de } \\
\text { programaçáo de computadores } \\
\text { utilizando o software Arduino } \\
\text { e elaboração dos } \\
\text { programas. }\end{array}$ & $\begin{array}{l}\text { Microprocessador } \\
\text { Arduino }{ }^{\oplus} \text { UNO. }\end{array}$ \\
\hline $\begin{array}{l}\text { Aula 4: } \\
\text { O cérebro }\end{array}$ & $\begin{array}{c}\text { Integração dos } \\
\text { conhecimentos } \\
\text { das aulas } \\
\text { anteriores }\end{array}$ & $\begin{array}{l}\text { Programação de acender e } \\
\text { piscar um LED controlado pelo } \\
\text { microprocessador Arduino }{ }^{\oplus} \text {. }\end{array}$ & $\begin{array}{l}\text { Arduino }{ }^{\oplus} \text { UNO, } \\
\text { protoboards, LEDs, } \\
\text { botoeiras, resistores e } \\
\text { fios para conexáo. }\end{array}$ \\
\hline $\begin{array}{c}\text { Aula 5: } \\
\text { Levantando } \\
\text { peso }\end{array}$ & $\begin{array}{l}\text { Montagem } \\
\text { mecânica }\end{array}$ & $\begin{array}{l}\text { Construção de um guindaste } \\
\text { utilizando o kit da Modelix }{ }^{\circledR} \text {. }\end{array}$ & Kit didático da Modelix \\
\hline $\begin{array}{c}\text { Aula 6: } \\
\text { Enxergando } \\
\text { o mundo }\end{array}$ & Eletrônica & $\begin{array}{l}\text { Funcionamento e utilização de } \\
\text { sensores como o de luz LDR } \\
\text { (Light Dependent Resistor - } \\
\text { Resistor Dependente de Luz), } \\
\text { o de temperatura LM35, o de } \\
\text { distância infravermelho e a } \\
\text { chave magnética (Reed Switch). }\end{array}$ & $\begin{array}{l}\text { Arduino }{ }^{\oplus} \text { UNO, } \\
\text { protoboards, LEDs, } \\
\text { botoeiras, resistores, } \\
\text { fios para conexão e } \\
\text { sensores (LDR, LM35, } \\
\text { infravermelho, Reed } \\
\text { Switch). }\end{array}$ \\
\hline $\begin{array}{c}\text { Aula 7: } \\
\text { Aprendendo } \\
\text { a andar }\end{array}$ & Programação & $\begin{array}{l}\text { Acionamento dos motores } \\
\text { de corrente contínua do } \\
\text { robô UAIrobots-Line, para } \\
\text { posteriormente realizar os } \\
\text { desafios de programá-lo } \\
\text { para desenvolver trajetos de } \\
\text { formatos de figuras geométricas. }\end{array}$ & $\begin{array}{l}\text { Robô UAIrobots- } \\
\text { Line projetado com a } \\
\text { estrutura construída } \\
\text { de acrílico utilizando o } \\
\text { Arduino }{ }^{\oplus} \text { UNO, como } \\
\text { ilustra a Figura } 1 .\end{array}$ \\
\hline
\end{tabular}


Continuação Tabela 1

\begin{tabular}{|c|c|c|c|}
\hline $\begin{array}{c}\text { Aula 8: } \\
\text { Aprendendo } \\
\text { a controlar }\end{array}$ & $\begin{array}{l}\text { Integração dos } \\
\text { conhecimentos } \\
\text { das aulas } \\
\text { anteriores }\end{array}$ & $\begin{array}{l}\text { Controle de posiçáo da parte } \\
\text { móvel do guindaste montado } \\
\text { na aula } 5 \text { utilizando o Arduino } \\
\text { por meio das informaçóes do } \\
\text { sensor de luz LDR. }\end{array}$ & $\begin{array}{l}\text { Kit didático da } \\
\text { Modelix }^{\oplus} \text {, sensor } \\
\text { LDR Arduino UNO, } \\
\text { lanternas, resistores e } \\
\text { fios para conexão. }\end{array}$ \\
\hline $\begin{array}{l}\text { Aula 9: } \\
\text { Primeiro } \\
\text { robô }\end{array}$ & $\begin{array}{l}\text { Montagem } \\
\text { mecânica }\end{array}$ & $\begin{array}{l}\text { Montagem mecânica do robô } \\
\text { UAI-Le. }\end{array}$ & $\begin{array}{l}\text { Robô UAI-Le projetado } \\
\text { utilizando a estrutura } \\
\text { construída de materiais } \\
\text { descartados, como CDs, } \\
\text { acrílico e garrafas PET, } \\
\text { utilizando o Arduino } \\
\text { UNO, como ilustra a } \\
\text { Figura } 2 \text {. }\end{array}$ \\
\hline $\begin{array}{c}\text { Aula 10: } \\
\text { Sai da frente }\end{array}$ & $\begin{array}{l}\text { Integração dos } \\
\text { conhecimentos } \\
\text { das aulas } \\
\text { anteriores }\end{array}$ & $\begin{array}{l}\text { Desenvolver a programação do } \\
\text { robô que desvia de obstáculos } \\
\text { utilizando o robô montado } \\
\text { UAI-Le, conectando um sensor } \\
\text { de distância infravermelho na } \\
\text { regiāo frontal do protótipo. }\end{array}$ & $\begin{array}{l}\text { Robô UAI-Le e sensor } \\
\text { infravermelho. }\end{array}$ \\
\hline $\begin{array}{l}\text { Aula } 11 \text { a 15: } \\
\text { Preparação } \\
\text { para a } \\
\text { MRCV }\end{array}$ & $\begin{array}{l}\text { Integração dos } \\
\text { conhecimentos } \\
\text { das aulas } \\
\text { anteriores }\end{array}$ & $\begin{array}{l}\text { Montagem da estrutura física } \\
\text { e programaçáo dos robôs para } \\
\text { Mostra de Robótica do Campo } \\
\text { das Vertentes. }\end{array}$ & $\begin{array}{l}\text { Kit didático da } \mathrm{LEGO}^{\circ} \text {, } \\
\text { Arduino }{ }^{\bullet} \mathrm{UNO}, \\
\text { componentes eletrônicos } \\
\text { de baixo custo, materiais } \\
\text { descartados, por } \\
\text { exemplo, embalagens } \\
\text { de sanduiches e isopor } \\
\text { para a construção da } \\
\text { estrutura dos robôs. }\end{array}$ \\
\hline $\begin{array}{l}\text { Aula } 16 \text { a 20: } \\
\text { Preparaçáo } \\
\text { para a ORCV }\end{array}$ & $\begin{array}{c}\text { Integração dos } \\
\text { conhecimentos } \\
\text { das aulas } \\
\text { anteriores }\end{array}$ & $\begin{array}{l}\text { Montagem da estrutura física } \\
\text { e programaçáa dos robôs para } \\
\text { Olímpiada de Robótica do } \\
\text { Campo das Vertentes. }\end{array}$ & $\begin{array}{l}\text { Arduino }{ }^{\oplus} \text { UNO, } \\
\text { componentes eletrônicos } \\
\text { de baixo custo, } \\
\text { materiais descartados, } \\
\text { como papeláo e capa } \\
\text { de caderno para a } \\
\text { construçáo da estrutura } \\
\text { dos robôs. }\end{array}$ \\
\hline
\end{tabular}




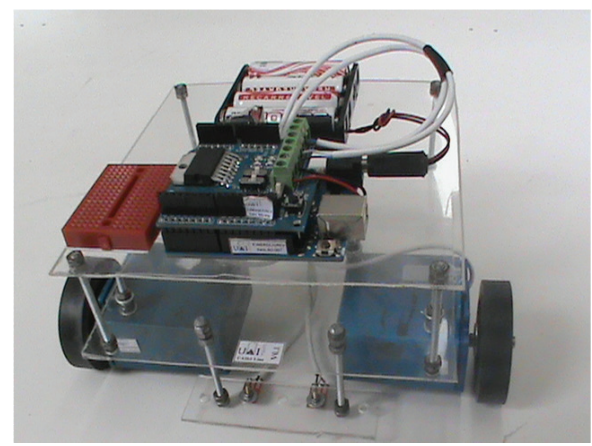

Figura 1: Robô seguidor de linha UAIrobots-Line projetado para as aulas de robótica.

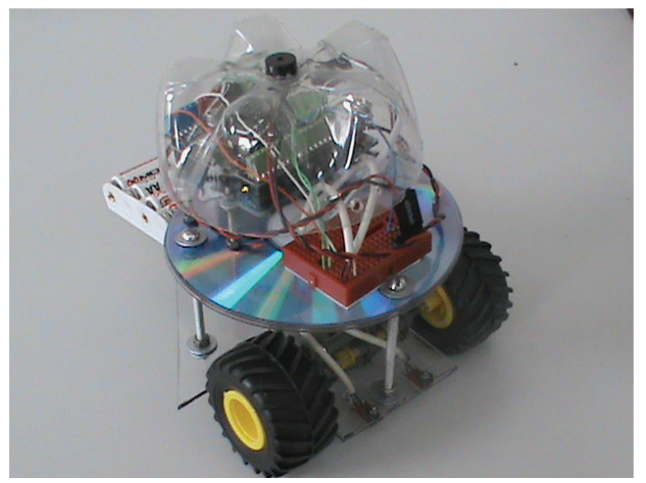

Figura 2: Robô seguidor de linha UAI-Le projetado para as aulas de robótica.

\section{Resultados da proposta de Robótica Inclusiva}

\section{Experiências obtidas durante o projeto}

No começo do projeto, as maiores preocupaçóes observadas dos graduandos em engenharia eram de como se relacionariam com os estudantes com deficiência, por essa ser a primeira experiência com esse público específico. Com o objetivo de trabalhar as expectativas, antes do início das aulas foi proposta uma conversa com as professoras dos cursos de Psicologia e de Letras, orientadoras do projeto, com os graduandos em engenharia responsáveis pelas aulas de robótica. Nessa reuniáo, muitos foram os questionamentos, como por exemplo: "O que eu deveria fazer se em alguma aula um aluno caçoar do aluno que tenha deficiência diante de sua limitação?", "O que eu devo fazer diante de uma possível crise do aluno esquizofrênico durante a aula?". As conversas incluíram orientaçóes como a questão da identidade do surdo e a importância da LIBRAS (GIAMMELARO, GESUELI e SILVA, 2013), características gerais da pessoa da síndrome de Asperger (TEODORO, CASARINI e SCORSOLINI-COMIN, 2013), e sobre a questáo do estigma e do preconceito e da importância de estratégias de manutenção de saúde para crianças e adolescências com transtornos mentais (LOUREIRO et al., 2014). 
Na sequência do projeto, foi proposta a divulgação nas escolas. Os graduandos apresentaram o projeto aos diretores das escolas e fizeram o convite para que estas escolas aderissem a ele, selecionando alguns de seus estudantes. Para que os alunos surdos participassem, foi necessário um intermédio por meio da Língua de Sinais, pois apenas o convite escrito era insuficiente para compreensão dos alunos sobre a temática do projeto.

Para a aula inaugural, foram convidados os pais dos participantes selecionados para que fosse explicado o funcionamento e todo o conteúdo do curso de robótica, além disso, os pais assinaram uma autorização para que seus filhos participassem. Também foi feita uma exibição demonstrativa de alguns robôs construídos pelos alunos dos cursos de engenharia.

Durante as aulas também foram observados resultados positivos com relação ao aluno com síndrome de Asperger. Nas primeiras aulas, ele apresentava um comportamento muito solitário, evitando conversar com o instrutor, monitores e colegas de aula. Com o passar das aulas, observou-se a interação desse aluno com as pessoas ao seu redor na busca por tentar cumprir o desafio proposto nas aulas de robótica. Bronfenbrenner (2011) fala da importância do meio no desenvolvimento de uma criança, e acreditamos que essa interação foi possível devido ao fato de as crianças dessa turma serem bem extrovertidas e comunicativas, dando oportunidade para que ele fizesse o mesmo.

Houve um episódio em que se percebeu comportamentos que indicavam preconceito em relaçáo a esse aluno por parte de uma colega de sala, na primeira aula do curso, durante a formação dos grupos entre os estudantes. Essa cena aconteceu quando a aluna em questão, ao final da aula, perguntou ao instrutor se iria ser o mesmo grupo até o restante do curso, demonstrando insatisfação. Na aula seguinte, essa aluna foi mudada para o outro grupo para evitar atitudes semelhantes a essa. Já as professoras e graduandos de Psicologia buscaram formular soluçóes para reverter essa situação. Entre as possíveis soluçóes, foi proposto observar uma ou mais atividades durante as aulas que esse aluno demonstrasse maior facilidade quando comparado à menina em questáo, para assim ela conseguir perceber que todas as pessoas têm dificuldades para realizar determinadas tarefas e que com deficiência ou não, cada um pode ter facilidades e dificuldades singulares. Sendo a Síndrome de Asperger caracterizada principalmente por interesses específicos e restritos ou preocupaçôes com um tema em detrimento de outras atividades, rituais ou comportamentos repetitivos, comportamento socialmente e emocionalmente impróprio e problemas de interação interpessoal, consegue-se justificar o comportamento do aluno (ERVIDEIRA, 2010).

Em relação aos participantes com déficit de aprendizagem e esquizofrenia, no início, apresentavam-se bem agitados e dispersos. O aluno com déficit de aprendizagem, mesmo com o auxílio do instrutor e do monitor, acompanhando-o bem de perto, demonstrava ter dificuldades de concentração nas atividades propostas durante as aulas. No final do projeto, foi possível perceber uma melhora em seu comportamento, destacando características positivas como demonstração de maior atenção e concentração nos desafios propostos e no trabalho em equipe, como por exemplo, na 
montagem e programação do robô escorpião para a participação na MRCV. Já o aluno esquizofrênico, infelizmente logo nas primeiras aulas, desistiu do curso e a equipe não conseguiu entrar em contato com a família para saber o motivo da desistência.

Apenas vinte e sete participantes finalizaram o projeto. As justificativas relatadas sobre as desistências foram variadas: um aluno por mudar de cidade, dez porque iniciaram cursos técnicos ou atividades extras escolares, dois porque moravam em áreas distantes da universidade, um por não ter uma pessoa responsável para levá-lo às aulas, um por incompatibilidade de horários e quatro não justificaram. Dois alunos surdos desistiram do projeto, sendo que um deles começou a trabalhar e não houve compatibilidade de horários e o outro assumiu a responsabilidade de cuidar do irmão mais novo em casa.

\section{Participação nos eventos de Robótica}

A Mostra de Robótica do Campo das Vertentes consiste numa mostra em que os participantes envolvidos no projeto exibem os robôs construídos para os pais, professores, familiares, amigos e interessados pela robótica. Uma forma da comunidade externa se interessar e prestigiar os trabalhos desenvolvidos na universidade. A Figura 3 ilustra alguns desses projetos, podendo citar: a) o aero barco, b) o robô limpa chão, c) a casa com placa solar inteligente e d) o robô seguidor de luz.
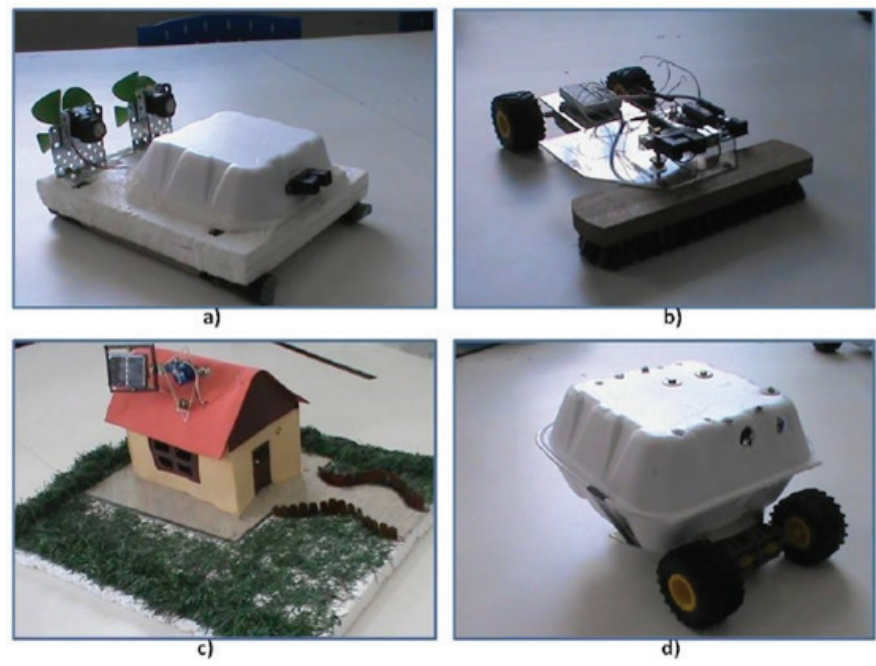

Figura 3: Projetos desenvolvidos pelos alunos e apresentados na MRCV 2013.

Já a Olimpíada de Robótica do Campo das Vertentes é uma competição entre os alunos do projeto visando proporcionar a interação entre eles além do trabalho em equipe para montarem e programarem um robô seguidor de linha.

Esses eventos também proporcionam a aplicação dos conhecimentos adquiridos pelos participantes no ambiente escolar. $\mathrm{Na}$ competição, cada equipe precisou que seus membros, diante de suas múltiplas habilidades, superassem suas limitaçôes e 
dificuldades para conseguir transpor as barreiras das diferenças individuais e focassem nas competências específicas de cada um. A Figura 4 exibe os robôs construídos pelos alunos para a competição.
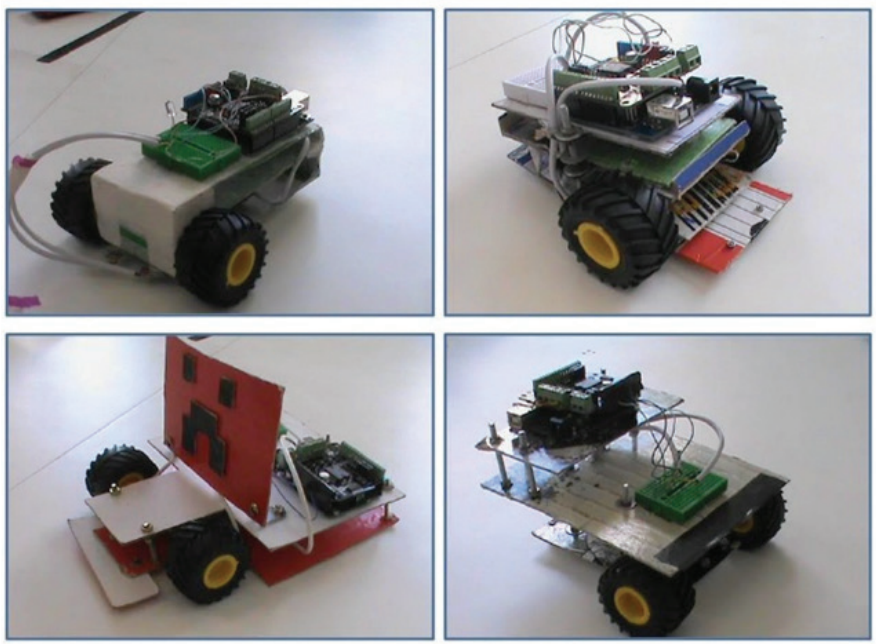

Figura 4: Robôs desenvolvidos pelos alunos para a ORCV 2013.

\section{Aprendizado dos participantes durante as atividades}

Logo ao início dos cursos, alguns participantes apresentaram dificuldades com relação ao uso do computador. A robótica proporcionou contribuir com a inclusão digital desses estudantes e aos que já tinham algum conhecimento possibilitou o seu aprofundamento, por meio do ensino de programação dos robôs, que nenhum deles havia tido contato.

Outro aspecto de grande relevância observado durante as aulas foi a interação dos surdos com os seus companheiros de equipe, podendo se destacar toda a calma e paciência desses estudantes ao tentarem se comunicar. A interaçáo entre os pares de surdos foi ainda melhor, uma vez que todos os alunos surdos envolvidos no projeto dominam, no mínimo, o básico de LIBRAS. De acordo com Lopes (apud SLKLIAR, 2011) os surdos, uma vez compartilhando a mesma língua, tem a oportunidade de auxiliarem uns aos outros, além de facilitar a organizaçáo de movimentos surdos. Assim, a escola onde os surdos estáo inseridos pode reconhecer e valorizar essa comunidade, cultura e identidade surda, identificando as características que formam esses contextos culturais. A integração também proporcionou despertar o interesse dos ouvintes por aprender LIBRAS, se destacando em alguns a facilidade com a datilologia e os principais sinais em LIBRAS.

Durante a preparação para as competições, os participantes apresentaram características importantes demonstrando espírito de cooperação, alguns de liderança e, sobretudo, de interesse pelo trabalho que estavam realizando. Analisando as características dos grupos formados, foi possível observar o quanto eles evoluíram nas habi- 
lidades de trabalhar em equipe, criatividade, pro-atividade e cuidado com o próximo. O simples fato da confiança em cada integrante do grupo os motivou a ir além de suas expectativas. Um caso observado foi o de uma aluna que tinha dificuldade de trabalhar em equipe por ter facilidade em entender os principais conceitos que eram expostos pelo instrutor. Ela sentiu necessidade da cooperação da equipe quando o desafio proposto era o de montar um robô, quando percebeu que as outras alunas tinham mais habilidades para estruturar o robô do que ela. Assim, ela se integrou de forma positiva ao grupo e ajudava as outras alunas quando se tratava de algo conceitual e aceitava que as alunas a ajudassem quando era necessário montar alguma parte do robô.

\section{Aprendizado dos estudantes de graduação}

Diante das análises e observaçóes realizadas durante as aulas, foi possível perceber que esses estudantes demonstraram características importantes, como criatividade, comprometimento, adaptabilidade, responsabilidade, motivação, planejamento, capacidade de trabalhar em equipe, dedicação, liderança, habilidades como falar em público, além de desenvolvimento em termos de conhecimento específico. Além disso, o contato com estagiários de áreas distintas, engenharia e psicologia, possibilitou novas formas de enxergar as soluçóes para possíveis problemas enfrentados no projeto. A integração entre essas áreas distintas permitiu identificar possíveis falhas com relação a didática durante as aulas que não eram percebidas pelos graduandos da engenharia, podendo ser observados avanços de todos os envolvidos no projeto em relaçáo a esses pontos.

O desenvolvimento da pesquisa e a oportunidade de passar os conhecimentos adquiridos na universidade para os estudantes das escolas públicas foram experiências extremamente gratificantes. $\mathrm{O}$ resultado deste trabalho refletiu diretamente na participação dos estudantes nos eventos de robótica, interesse e prazer que estes demonstraram ao cumprir os desafios que lhes foram propostos. Os processos proximais são bidirecionais (POLONIA, DESSEN, \& PEREIRA-SILVA, 2005), para Bronfenbrenner $(1979,1996,2011)$, as interaçóes entre as pessoas são recíprocas, não apenas um dos lados se desenvolve, mas a interação permite desenvolvimento de ambas as partes, e foi possível a observação dessa bidirecionalidade neste projeto. Não apenas por ficar nítido o desenvolvimento das crianças participantes, mas também dos estagiários envolvidos. A participação desses alunos de graduação no projeto de extensão contribuiu na sua formação e também na articulação dos conhecimentos teóricos e práticos na universidade, proporcionando a esses estudantes uma visão mais ampla e concisa da profissão almejada na graduaçáo. Esse projeto também pôde oferecer maior segurança para os graduandos decidirem os rumos a serem seguidos após a conclusão do curso superior, despertando, assim, em alguns o interesse por iniciar o mestrado e seguir a área acadêmica.

Por fim, quando questionados quanto ao interesse em continuar participando de projetos de extensão em uma entrevista ocorrida ao final do projeto, os envolvidos responderam que gostariam de permanecer desenvolvendo esses trabalhos em prol da comunidade. Além disso, alguns relataram com maior entusiasmo todos os benefí- 
cios alcançados tanto pessoais quanto profissionais. Neste sentido, outros projetos de extensão em robótica estão sendo elaborados, a fim de envolver mais estudantes de graduação e de escolas públicas.

\section{Considerações finais}

Ter a oportunidade de trabalhar com pessoas de uma realidade social diferente, com pessoas com deficiência e aprender a lidar com esses desafios foi uma experiência de enorme aprendizado. $\mathrm{O}$ contato diário com as crianças e adolescentes possibilitou perceber que é importante oferecer as possibilidades de desenvolvimento propostas por Bronfenbrenner $(2011,1996)$. Pode-se destacar os participantes surdos pelo interesse, conhecimento e a vontade de superar as suas limitaçôes e como os outros participantes se dispunham a ajudar e entender a dificuldade do próximo, realmente é uma experiência gratificante a todos realizadores do projeto.

Durante as aulas, foi relatado pelos estudantes de graduaçáo que esse era o primeiro contato com crianças e adolescentes no papel de professor e havia preocupação em como agir com os estudantes com deficiência. Entretanto, ao prosseguir e visualizar que esse projeto pode de alguma maneira fazer a diferença na vida de cada pessoa ou até mesmo para um bem social, foi um fator determinante para despertar o lado humano dos graduandos. Diante da possibilidade de contribuir de alguma forma para o desenvolvimento pessoal e profissional destes e com a sociedade em geral, foi possível perceber que atitudes simples podem fazer uma grande diferença na vida dessas pessoas, resultando numa sensação de dever cumprido pelos realizadores do projeto.

Por fim, com relação à hipótese que esse projeto pretendeu verificar: "Se em um grupo heterogêneo, iráo se sobressair as qualidades individuais de cada elemento, para o bem do grupo, em detrimento de seus limitantes físicos e/ou cognitivos", concluiu-se que o trabalho em equipe dos alunos superou suas limitaçôes físicas e cognitivas.

\section{Agradecimentos}

À Fundação de Amparo a Pesquisa do Estado de Minas Gerais (FAPEMIG), pelo apoio financeiro, à Universidade Federal de São Joáo del-Rei (UFSJ), pelo apoio logístico e infraestrutura física. A todas as escolas envolvidas pela participação e parceria, aos professores dessas escolas, estudantes de graduaçáo e professores da UFSJ pelo auxílio durante a execução desse projeto.

\section{Referências}

AMORIN, F. A. et al. Uma Experiência Educativa de Robótica em Bairros de Vulnerabilidade Social de Vitória da Conquista - Bahia. Revista Extensáo \& Cidadania, Vitória da Conquista, v. 1, n. 2, p. 53-69, jul/dez. 2013

AZEVEDO, S. et al. Introduçáo a Robótica Educacional, Campinas, 1999, Disponível em: <http://www. uesb.br/mat/semat/seemat2/index_arquivos/mc5.pdf> Acesso em: 25 ago. 2014

BRONFENBRENNER, U. The ecology of human development. Cambridge (US): Harvard University Press, 1979. 
Lídia Lopes - Larissa Medeiros Marinho dos Santos - Luis Fernando Freire de Souza - Marcio Falcão

Santos Barroso - Cleuzilaine Vieira da Silva - Bruna Reis Serpa - Eduardo Bento Pereira

BRONFENBRENNER, U. Bioecologia do desenvolvimento humano: tornando os seres humanos mais humanos. Porto Alegre: Artmed, v. 2, 2011.

. A ecologia do desenvolvimento humano: experimentos naturais e planejados (M. A. Veríssimo, Trad.). Porto Alegre: Artes Médicas. (Trabalho original publicado em 1979). 1996.

ERVIDEIRA, A. Apoio a crianças com necessidades educativas especiais no âmbito das atividades de enriquecimento curricular. Revista Animaçáo e Educaçáo, 2010.

GALVÃO FILHO, T. A.; DAMASCENO, L. L. Tecnologia Assistiva em Ambiente Computacional Recursos Para a Autonomia e Inclusão Socio-digital da Pessoa com Deficiência. Programa InfoEsp: Premio Reina Sofia 2007 de Rehabilitación y de Integración. In: Boletín del Real Patronato Sobre Discapacidad, Ministerio de Educación, Política Social y Deporte, Madri, Espanha, n. 63, p. 14-23, ISSN: 1696-0998, abril/2008.

GIAMMELARO, C. N. F.; GESUELI, Z. M.; SILVA, I. R. A relação sujeito/linguagem na construçấo da identidade surda. Educaçáo \& Sociedade, v. 34, n. 123, p. 509-527, 2013.

LOUREIRO, L. et al. Rótulos psiquiátricos: bem-me-quer, mal-me-quer, muito, pouco e nada. Revista Portuguesa de Enfermagem de Saúde Mental, n. SPE1, p. 40-46, 2014.

LOURENÇO, A. A; PAIVA, M. O. A. de. A motivação escolar e o processo de aprendizagem. Ciências e Cogniçáo/Science and Cognition, v. 15, n. 2, 2010.

MENEZES, E. T. de; SANTOS, T. H. dos. "Robótica educacional" (verbete). Dicionário Interativo da Educação Brasileira - EducaBrasil. São Paulo: Midiamix Editora, 2002, Disponível em: <http://www.educabrasil.com. br/eb/dic/dicionario.asp?id=49>, Acesso em: 25 ago. 2014.

PIO, J. L. S.; CASTRO, T. H C.; CASTRO JUNIOR, A. N. A Robótica Móvel como Instrumento de Apoio à Aprendizagem de Computação. Anais: do XVII - Simpósio Brasileiro de Informática na Educação, 2006 nov. 08-10: Brasília.

POLONIA, A. C., DESSEN, M. A.; PEREIRA-SILVA, N. L. O modelo bioecológico de Bronfenbrenner: contribuiçōes para o desenvolvimento humano. In: DESSEN, M. A.; COSTA JUNIOR ,A. L. (Orgs.). A ciência do desenvolvimento humano: tendências atuais e perspectivas futuras (p. 71-89). Porto Alegre: Artmed, 2005. REGO, T. C. Vygotsky: uma perspectiva histórico-cultural da educação. 14a edição. Petrópolis, RJ: Vozes, 2002. p. 58

REIS, G. L. et al. Integração entre ensino médio e engenharia por meio de atividades extensionistas na área de robótica e inclusão digital. In: XXXIX Congresso Brasileiro de Educação em Engenharia, 2011, Blumenau. Anais do XXXIX Congresso Brasileiro de Educação em Engenharia, 2011.

REIS, G. L. et al. A relevância da extençấo para os cursos de engenharia: um estudo de caso do projeto a robótica e a inclusão digital: Uma visão extensionista. In: Congresso Brasileiro de Automática, 2012, Campina Grande. Anais do XIX Congresso Brasileiro de Automática, 2012.

REIS, G. L. et al. A relevância da integraçấo entre universidades e escolas: um estudo de caso de atividades extensionistas em robótica educacional voltadas para rede pública de ensino. Interfaces-Revista de Extensáo da UFMG, v. 2, n. 3, p. 52-76, 2015.

RODRIGUES, C. L. L. Robótica educacional em ambiente educativo em anos iniciais do ensino superior. Rio Grande, 2009. Disponível em: <http://www.academia.edu/781689/ROBOTICA_EDUCACIONAL_EM_AMBIENTE_EDUCATIVO_EM_ANOS_INICIAIS_DO_ENSINO_SUPERIOR $>$ Acesso em: 25 ago. 2014

SANTOS, T. N.; POZZEBON, E.; FRIGO, L. B. Robótica aplicada à Educaçáo Especial. Florianópolis. 2013. Disponível em <http://www.icbl-conference.org/proceedings/2013/papers/Contribution43_a.pdf> Acessado em: 25 ago. 2014.

SILVA, A. A. R. S. da. et al. A robótica pedagógica no contexto da educaçáo infantil: Auxiliando o alfabetismo. In: I Congresso de Tecnologias na Educação-27 de outubro e 1o de. 2008. p. 9.

SILVA, A. A. R. S. Robótica e Educação: Uma possibilidade de inserção sócio-digital. 2010. 146 p. Tese (Mestrado em Educaçáo) - Programa de Pós-Graduação em Educação de Ciências Sociais Aplicadas da Universidade Federal do Rio Grande do Norte, Natal.

SILVA, A. F. da. et al. Utilizaçáo da teoria de Vygotsky em robótica educativa, Caracas, 2008. Disponível em: <http://www.ufrgs.br/niee/eventos/RIBIE/2008/pdf/utilizacion_teoria_vygotkski_robotica.pdf>. Acesso em: 25 ago. 2014. 
SILVA, F. S. RoboEduc: uma metodologia de aprendizado com robótica educacional. 2009. 127 p. Dissertaçấo (Doutorado em Engenharia de Computação) - Programa de Pós-Graduação em Engenharia Elétrica da UFRN, Natal.

SLKILIAR, C. A surdez: um olhar sobre as diferenças, 5. ed. Porto Alegre: Mediaçăo. 2011. 190 p.

SOUZA, L. F. F. ; REIS, G. L. ; PEREIRA, E. B. A robótica educacional como elo de integraçâo entre o ensino fundamental e de graduaçáo pelo uso da linguagem logo. In: III Workshop de Robótica Educacional, 2012, Fortaleza. Anais do III Workshop de Robótica Educacional, 2012.

STEFFEN, H. H. Robótica pedagógica na educaçáo: um recurso de comunicação, regulagem e cogniçấo. 2002, xiii, 113 f. Dissertação de Mestrado - Escola de Comunicações e Artes, Universidade de São Paulo, São Paulo.

TEODORO, M. C.; CASARINI, K. A.; SCORSOLINI-COMIN, F. Intervençóes terapêuticas em pessoas com Síndrome de Asperger: revisão da literatura. Barbaroi, n. 38, p. 6-25, 2013.

ZILLI, S. R. A robótica educacional no ensino fundamental: Perspectivas e prática. 2004. 89p Dissertação de Mestrado. Dissertação (Mestrado em Engenharia de Produção) - Programa de Pós-Graduação em Engenharia de Produção, Universidade Federal de Santa Catarina, Florianópolis.

\section{Correspondência}

Larissa Medeiros Marinho dos Santos - Departamento de Psicologia da UFSJ/Campus Dom Bosco.

Praça Dom Helvécio 74. Fábricas. São João del Rei, Minas Gerais, CEP: 36301-160, Brasil.

E-mail: lidiamaralopes@gmail.com - larissa@ufsj.edu.br - lnandoffs@hotmail.com - barroso@ufsj.edu.br cleuzilaine@ufsj.edu.br - brunaserpa12@gmail.com - ebento@ufsj.edu.br

Recebido em 17 de outubro de 2014

Aprovado em 19 de março de 2015 